\title{
Long-term decrease in sex-specific natural mortality of European lobster within a marine protected area
}

\author{
Even Moland $^{1, *}$, Mats Ulmestrand ${ }^{2}$, Esben Moland Olsen ${ }^{1,3,4}$, Nils Chr. Stenseth ${ }^{3}$ \\ ${ }^{1}$ Institute of Marine Research, Flødevigen Marine Research Station, 4817 His, Norway \\ ${ }^{2}$ Swedish University of Agricultural Sciences, Institute of Marine Research, PO Box 4, 45321 Lysekil, Sweden \\ ${ }^{3}$ Centre for Ecological and Evolutionary Synthesis (CEES), Department of Biosciences, University of Oslo, \\ PO Box 1066 Blindern, 0316 Oslo, Norway \\ ${ }^{4}$ Department of Natural Sciences, Faculty of Science and Engineering, University of Agder, 4604 Kristiansand, Norway
}

\begin{abstract}
Marine protected areas (MPAs) and marine reserves hold promise as tools for nature conservation and fisheries management, but data on long-term demographic effects are still sparse. Here, we use a unique capture-mark-recapture data set from Kåvra, an MPA on the west coast of Sweden where fishing for European lobster Homarus gammarus has been banned since 1989, to directly quantify annual survival probabilities in the absence of harvest mortality. The non-migratory behaviour of this species allowed multiple recaptures and releases of a large number of individuals within the MPA. We found strong evidence for a long-term decrease in sexspecific natural mortality throughout the study period (1994 to 2007). Positive trends were evident in mean body size and in catch-per-unit-effort, the latter indicating an increase in abundance. Together, these findings suggest that after nearly 2 decades of protection, density dependence was still not halting development of the population within the MPA. The present study is the first to quantify long-term (14 yr) changes in natural mortality rates in a protected marine population. Moreover, our study supports the notion that MPAs and marine reserves may act to counter fisheries-induced selection.
\end{abstract}

KEY WORDS: Capture-mark-recapture · Demography · Density-dependence · Fisheries · Fitness · Homarus gammarus · Marine reserves · Sex-specific survival

\section{INTRODUCTION}

Over the last decade, marine reserves have received unmatched attention as a versatile tool in fisheries management and conservation. A plethora of recent studies has documented effects, discussed design and explored potential applications of marine reserves (e.g. Halpern \& Warner 2003, Claudet et al. 2008, Russ et al. 2008, Game et al. 2009, Babcock et al. 2010). Fisheries typically remove large and old individuals, leading to 'longevity overfishing' (Berkeley et al. 2004, Beamish et al. 2006). Importantly, as marine reserves counteract the effects of longevity

*Email: even.moland@graduates.jcu.edu.au overfishing (i.e. restore and maintain broad size and age structures in harvested species), they simultaneously protect against strong fisheries-based selection for earlier maturation (e.g. Baskett et al. 2005). Because of this, marine reserves are perceived as an integral part of ecosystem-based fisheries management and a critical component of successful rebuilding efforts (e.g. Lubchenco et al. 2003, Francis et al. 2007, Worm et al. 2009).

However, the concept of marine reserves is subject to a theoretical debate regarding its potential and limitations as a fisheries management tool (e.g. Lizaso et al. 2000, Jones 2007 and references there-

() The authors 2013. Open Access under Creative Commons by Attribution Licence. Use, distribution and reproduction are unrestricted. Authors and original publication must be credited. 
in). Recently, a modelling study by Gårdmark et al. (2006) hypothesized that density-dependent processes are likely to erode benefits of marine reserves to fisheries. The proposed operating mechanism is that because of crowding effects, density-dependent body growth (Lorenzen \& Enberg 2002) will result in reduced size at a given age in protected populations. Also, the authors hypothesized that the same effect will eventually manifest itself even in the fished population because of higher density through larval input from the reserve. However, the long-term demographic consequences of protection are poorly understood, largely owing to sparseness of available empirical data (Jones 2007). Such data are urgently needed, e.g. in light of the recent study by Anderson et al. (2008) in which the authors showed that harvesting can lead to increased instability in population dynamics through 'juvenescence' and subsequent changes in demographic parameters.

The strongest responses to protection in MPAs and marine reserves have been shown in species with moderate mobility and exposure to high levels of fishing mortality (e.g. Micheli et al. 2004, Goñi et al. 2010). Lobsters, which are highly valued target species in commercial and recreational fisheries and can have relatively limited home ranges (e.g. Follesa et al. 2009, Moland et al. 2011), may respond quickly to protection even in small MPAs. In the Maria Island reserve, Tasmania, Edgar \& Barret (1999) showed an increase of more than an order of magnitude in rock lobster Jasus edwardsii biomass over a 6 yr period following protection from fishing. Since then, positive responses to protection have been documented for several additional lobster species, e.g. American lobster Homarus americanus (Rowe 2002), spiny lobster Palinurus elephas (Goñi et al. 2010) and, recently, European lobster Homanus gammarus (Hoskin et al. 2011, Moland et al. 2013). In the past, the main focus of most published studies has been the monitoring of changes in biomass, density and body size of protected lobster populations, as well as detection of spillover effects (e.g. Goñi et al. 2006, 2010). However, recent studies by Bevacqua et al. (2010) and Goñi et al. (2010) have demonstrated reduced mortality rates in the spiny lobster $P$. elephas after 7 and $17 \mathrm{yr}$ of protection, respectively, in 2 Mediterranean MPAs.

Herein, we test for evidence of a long-term trend in survival in a population of European lobster on the Swedish Skagerrak coast protected from harvesting within an MPA since 1989. The Kåvra MPA was created for research purposes with the objective of studying the development of a lobster population within a limited area in the absence of harvesting (see Øresland \& Ulmestrand 2013). Specifically, we estimate sex-specific survival probability from a unique long-term capture-mark-recapture data set that was collected in the MPA from 1994 to 2007. Previous capture-mark-recapture studies suggest that European lobsters rarely move more than a few kilometres for periods up to years (e.g. Dannevig 1936, Smith et al. 2001, Agnalt et al. 2007). In a recent telemetry study, Moland et al. (2011) showed that European lobsters can display high site fidelity and limited home range size. During the course of $1 \mathrm{yr}$, adult lobsters monitored each used less than $5 \%$ of the habitat present in the Flødevigen lobster reserve $\left(1 \mathrm{~km}^{2}\right)$. The non-migratory behaviour of this species allowed multiple recaptures and releases of a large number of individuals within the Kåvra MPA area.

Here, we estimate sex-specific annual survival probabilities in the Kåvra lobster population. We combine the survival estimates with data on changes in body size within the MPA and data on changes in catch-per-unit-effort (CPUE) within and outside the MPA to assess long-term effects of protection on European lobster and evaluate their implications for harvested populations.

\section{MATERIALS AND METHODS}

\section{Study species}

The European lobster is a large, long-lived decapod crustacean of ecological and commercial importance, distributed from the north of Norway to Morocco in North Africa (Triantafyllidis et al. 2005). European lobster longevity may potentially span several decades, during which large specimens may grow to weights up to $10 \mathrm{~kg}$. Average age of large (150 to $170 \mathrm{~mm}$ carapace length, CL) male and female specimens has been estimated as high as 31 and $54 \mathrm{yr}$, respectively, based on accumulation of lipofuscin in the eyestalk ganglion (Sheehy et al. 1999). The same study estimated that the $80-89.9 \mathrm{~mm}$ CL size class contained males that were 3.5 to $12.9 \mathrm{yr}$ old and females that were 4.1 to $13.0 \mathrm{yr}$ old. Growth studies conducted in southern Norway have estimated average growth increments of $\approx 7 \mathrm{~mm} C L$ at each moult for females, with a 2 yr moult cycle being the predominant pattern (Agnalt et al. 2007). Based on data from wild-caught females, size at maturity is usually $\approx 80 \mathrm{~mm}$ CL (Agnalt 2008). In Swedish waters, lobsters are legally caught in traps from the first Monday after 20 September to 30 April. Minimum legal size (MLS) 
is $80 \mathrm{~mm} \mathrm{CL}$, and there is a ban on capture and trade of ovigerous females. Legal traps must be fitted with 2 circular escape vents $\geq 54 \mathrm{~mm}$ in diameter to reduce capture of lobsters below MLS.

\section{Data collection}

Data reported in the present paper are from the Kåvra MPA and surrounding areas, near Lysekil on the Swedish west coast $\left(58.33^{\circ} \mathrm{N}, 11.36^{\circ} \mathrm{E}\right)$. The $2.1 \mathrm{~km}^{2}$ MPA is situated near shore and dominated by exposed and submerged bedrock islets separated by channels 10 to $25 \mathrm{~m}$ deep (Fig. 1). The substratum of the channels largely consists of sediments (sand or mud). The MPA is situated in an area historically known as productive lobster fishing grounds. Commercial and recreational capture of lobster has been absent in the MPA since 1989 through a ban on fixed gear (e.g. gill nets, fyke nets, traps, pots). Establishment of the MPA and a complementary baseline study was initiated by the Swedish Board of Fisheries, Institute of Marine Research, Lysekil. The MPA ban on fishing has been enforced, and very few instances of traps set within MPA borders have been reported. Such instances have without exception been due to misunderstandings rather than deliber- ate attempts at poaching (M. Ulmestrand unpubl. data). Experimental fishing was conducted with baited shellfish fyke nets up to and including the 1999 sampling season. In 1999, a set of standard commercial-style parlour lobster traps, without escape vents, was introduced alongside the fyke nets. From 2000 onwards, fishing was conducted exclusively with lobster traps. The lobster data were obtained yearly from May (earliest) through October (latest). Average soak time was 7.5 d (1999 to 2007, see CPUE calculations in the supplement at www.int-res.com/ articles/suppl/m491p153_supp.pdf). Sampling effort varied both within and among years (Table S1 in the supplement). Fishing was carried out by the same group of researchers throughout the study. Although additional lobsters were tagged in 2007, only those recaptures made in 2007 were included in our analysis since no survival or recapture parameters are quantifiable for individuals with only one encounter (Lebreton et al. 1992). Lobsters were tagged with individually numbered T-bar anchor tags (Floy Tag, $50 \times 2 \mathrm{~mm}$ ). Tags were inserted in the ventral musculature between the cephalothorax and abdomen to the right side of the midline using a standard tag applicator. Lobsters were sexed, measured and tagged immediately upon capture and released at the site of capture. CL was measured from the rear of

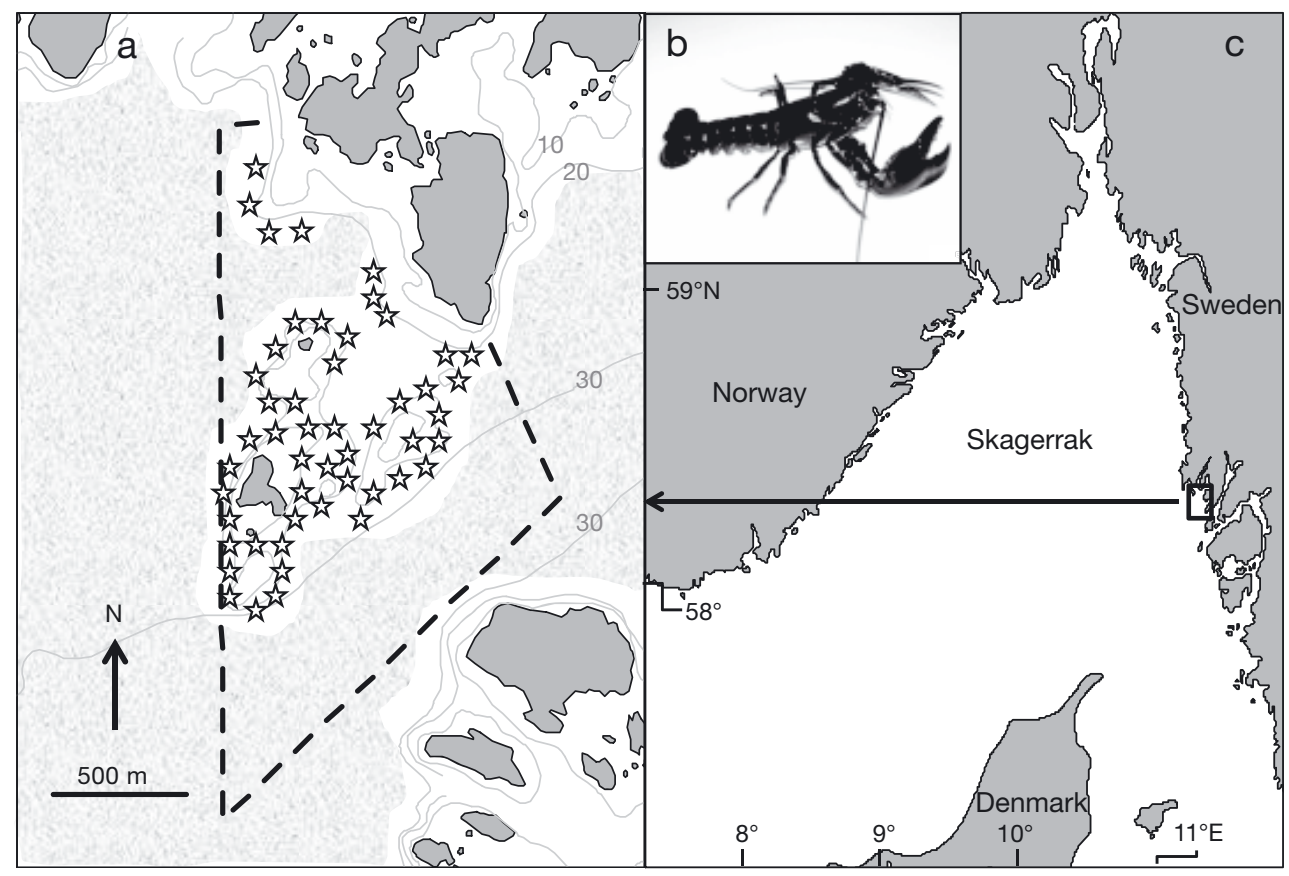

Fig. 1. (a) Kåvra marine protected area (MPA) protecting (b) European lobster on the (c) Swedish Skagerrak coast. Dashed black line: MPA boundary. Stars indicate lobster habitat/areas where sampling gear was deployed throughout the study. Texturing indicates areas with predominantly soft substrate (sand or mud). Numbers in grey are contour depths 
the eye socket to the posterior margin of the carapace to the nearest millimeter using vernier callipers, and sex was determined by examination of the first pair of pleopods.

Throughout the present study, some lobsters tagged inside the Kåvra MPA were caught by commercial and recreational fishers outside the protected area. When reporting these recoveries, fishers generally supplied sex and size, date of catch, tag number and position of recapture. In many cases, the recaptured tag was supplied along with a reporting letter. We have summarized these reports and quantified the distance from the MPA centre to reported recovery position for each reported case.

CPUE data reported in fishers' voluntary catch diaries from areas outside the MPA were available for the study period (data from area $7 \mathrm{a}-\mathrm{b}$ as described in Sundelöf et al. 2013).

\section{Data analyses}

We applied a capture-mark-recapture modelling approach advocated by Lebreton et al. (1992) to generate estimates of survival and recapture probabilities. Capture-mark-recapture modelling was implemented using the program MARK (Version 4.3) with a logit link function to constrain estimates between 0 and 1 (White \& Burnham 1999). We assessed liverecaptures-only models, as the quantity of dead recoveries was small. Moreover, most dead recoveries in the data set were either accidental deaths attributable to trapping (mortality from lobsters fighting while being locked in traps) or represent individuals caught outside the reserve by lobster fishers. Dead recoveries were coded as censored on last capture, i.e. coded as -1 , in the MARK input file. Liverecaptures-only models generate estimates of apparent survival probability $(\Phi)$, which is the probability that a lobster has not died or emigrated from the study population, and capture probability $(\mathrm{P})$, which is the probability that a lobster that is present in the study population is caught. It is important to note that in this type of modelling, the effect of change of gear, effort, release rate, recapture rate or environment during the time series will be handled by the capture probability parameter (P) (Lebreton et al. 1992). We modelled the data with males and females as separate groups to test for sex-specific survival and capture probabilities. The reason for including this a priori distinction is that management rules are sexspecific (ban on capture of egg-bearing females); also, available information on longevity suggests that females might have higher survival probabilities in the wild (Sheehy et al. 1999), although confounding effects of capture probability remain unaccounted for. Instantaneous total mortality $(Z)$ was estimated as $-\log (\Phi)$ (see Bjorndal et al. 2003a). In the absence of fishing mortality, $Z=$ natural mortality $(M)$.

We evaluated the goodness of fit (GoF) of the full parameter ('global') Cormack-Jolly-Seber model (sex- and time-dependent survival and recapture probabilities) using RELEASE TEST2+ 3 available in MARK (White \& Burnham 1999). Second, we used UCARE (Choquet et al. 2009), which implements the extended form of TEST2+3 originally derived by Burnham et al. (1987), to evaluate recapture heterogeneity with TEST2.Ct (Pradel 1993). TEST2.Ct tests for specific behavioural patterns, such as recapture heterogeneity or temporary emigration, which mimic trap dependence. Selection of the best model from a series of models was based on the quasi-likelihood corrected form of the Akaike Information Criterion (QAICc) (Anderson et al. 1998).

Mean CPUE within the MPA was calculated separately for the 2 gear types used during 1994 to 1999 (shellfish fyke nets) and during 1999 to 2007 (lobster traps, see Table S1 and CPUE calculations in the supplement). Mean CPUE from area 7a-b outside the MPA was used without the adjustment for technological creep described in Sundelöf et al. (2013).

All lobsters captured and recaptured were used to calculate mean size (CL). In cases where lobsters were encountered multiple times during the same season, only the first measure was used. We used a classical linear model (McCullagh \& Nelder 1999) to test for effects of sex (s) and MPA age (year, $Y$ ) on the mean carapace length of lobsters:

$$
\mathrm{CL}=\beta_{0}+\beta_{1, s}+\beta_{2} Y+\beta_{3, s} Y
$$

A linear model was also used to test for an effect of MPA age $(Y)$ on mean CPUE:

$$
\text { CPUE }=\beta_{0}+\beta_{1} Y
$$

The same model structure was used to test for an effect of time on mean CPUE from areas outside the MPA. Residual plots indicated that models fitted the data adequately.

\section{RESULTS}

\section{Lobster captures and recaptures}

From 1994 through 2006, 1538 male and 1753 female lobsters were tagged in the Kåvra MPA. Of 

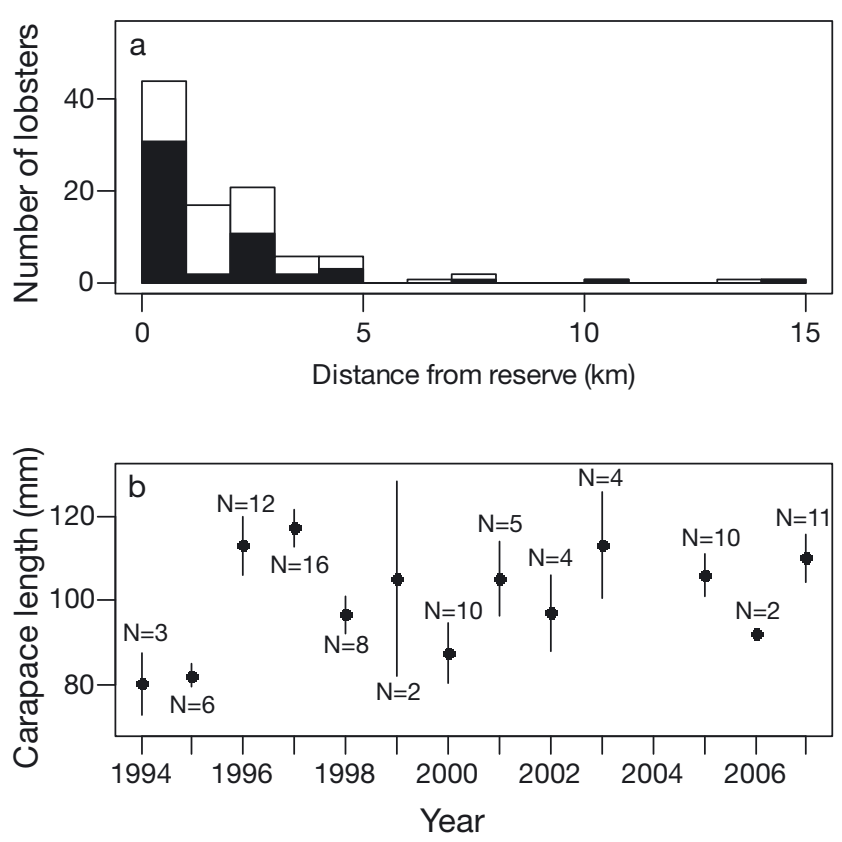

Fig. 2. Homarus gammarus. (a) Recapture distance (from marine protected area [MPA] centre), and (b) size and number of lobsters recaptured outside the Kåvra MPA by fishers operating in the area during 1994 to 2007. Open bars: females, black bars: males. Data in (b) are mean carapace lengths $\pm \mathrm{SE}$. $\mathrm{N}=$ number of outside recaptures used in the calculation of mean size for each year $($ sum $=93)$. Eight additional outside recaptures were not included as they were reported without size information. No outside recaptures were reported in 2004 these, 641 males and 729 females were recaptured at least once within the study area with the tag intact (excluding dead recoveries and emigrants). Some individuals were recaptured multiple times within the same sampling season, but only one capture per individual in a year was used in the present analysis ( $\mathrm{n}=2498$ recapture episodes). In most cases, the first recapture occurred in the year following initial release, but some individuals did not show up in the catches until several years after tagging (see Table S2 in the supplement). A total of 127 dead recoveries (male $\mathrm{n}=70$, female $\mathrm{n}=57$ ) were recorded throughout the study period. Of these, 101 individuals were emigrants (male $n=53$, female $\mathrm{n}=48$ ) caught outside MPA borders by local fishers; $42 \%$ of the emigrants were caught less than $1 \mathrm{~km}$ from the MPA centre, and $12 \%$ of the emigrants were caught more than $4 \mathrm{~km}$ from the MPA centre (Fig. 2).

\section{Body size and CPUE}

Mean body size of both male and female lobsters increased by $23 \%$ throughout the study period (Fig. 3a). For male lobsters ( $\mathrm{n}=2685)$, mean CL increased from $87.6 \mathrm{~mm} \pm 21.6 \mathrm{SD}$ in 1994 to $107.9 \mathrm{~mm}$ \pm 17.5 SD in 2007. For female lobsters $(\mathrm{n}=3104)$, mean CL increased from $83.7 \mathrm{~mm} \pm 17.5 \mathrm{SD}$ in 1994
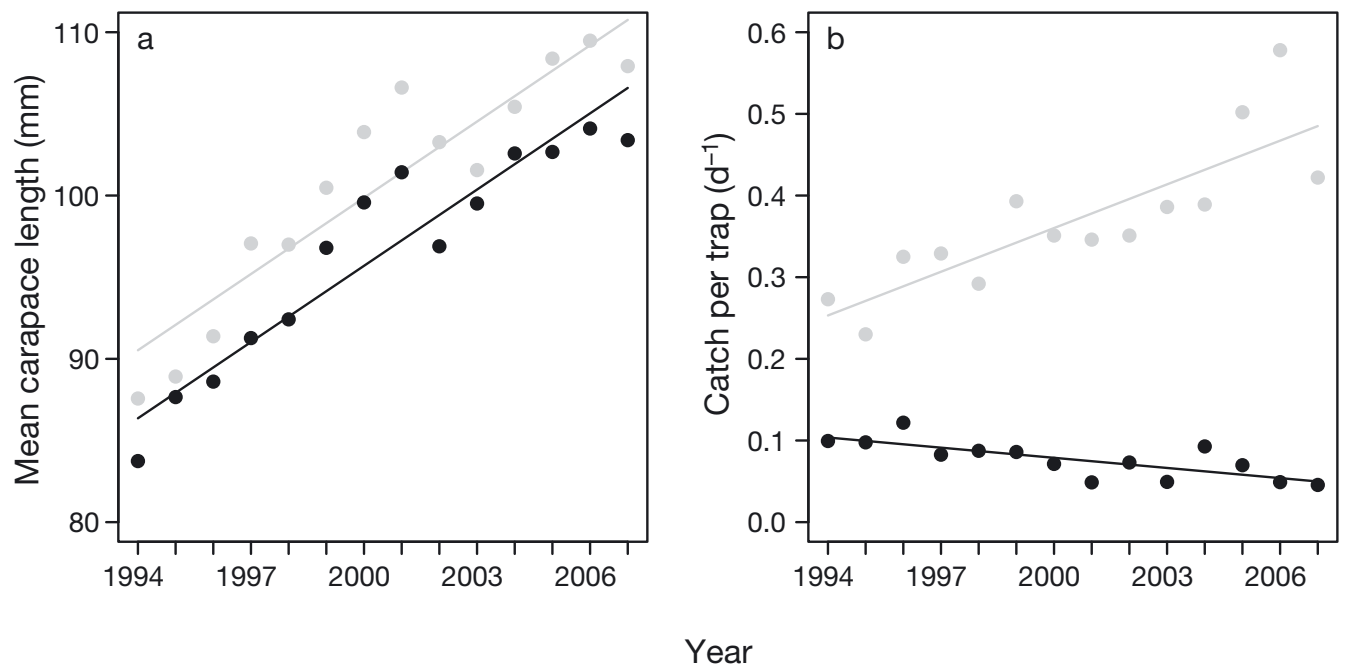

Fig. 3. Homarus gammarus. (a) Annual mean body size of male (grey) and female (black) lobsters from the Kåvra marine protected area (MPA), and (b) annual catch-per-unit-effort (CPUE) inside (grey) and outside (black) the Kåvra MPA. Lines represent slopes fitted to data using linear models. Model $\mathrm{R}^{2}(\mathrm{a})=0.89$, (b) inside MPA (grey) = 0.69 and outside MPA (black) =0.54 . Annual CPUE inside the MPA is the mean of standardized CPUE for each gear haul in a sampling season (see supplement). Mean CPUE outside the MPA is calculated from voluntary catch diaries reported by fishers near the Kåvra MPA (area $7 a-b$, see Sundelöf et al. 2013). Catch = number of lobsters 
to $103.4 \mathrm{~mm} \pm 15.7 \mathrm{SD}$ in 2007 . There were significant additive effects of sex and reserve age (year) on the mean CL of lobsters $(p<0.001)$. The interaction effect between sex and year was not significant $(p=$ 0.61). Overall, females tended to be smaller than males $\left(\beta_{1}=-4.17, \mathrm{SE}=0.95\right)$. Throughout the study period, the predicted increase in mean size was about $1.6 \mathrm{~mm}$ per year $\left(\beta_{2}=1.56, \mathrm{SE}=0.12\right)$.

There was a significant increase in CPUE throughout the study period corresponding to about 2 lobsters per 100 trap days per year $\left(\beta_{1}=0.018, \mathrm{SE}=\right.$ $0.0034, \mathrm{p}<0.001$, Fig. $3 b$ ). Conversely, there was a significant decrease in CPUE in areas near the Kåvra MPA throughout the study period, corresponding to 0.4 lobster per 100 trap days per year $\left(\beta_{1}=-0.004\right.$, $\mathrm{SE}=0.001, \mathrm{p}<0.01$, Fig. 3b)

\section{Annual survival and recapture probabilities}

The Cormack-Jolly-Seber model passed GoF TEST3 ('the survival test') of RELEASE for both sexes combined $\left(\chi^{2}=52.29\right.$, df $\left.=46, \mathrm{p}=0.243\right)$, indicating that transience was not a problem. When looking at TEST3 results for the 2 sexes separately, the model passed TEST3.SR for males $\left(\chi^{2}=5.26\right.$, df $=12, \mathrm{p}=0.948)$ and females $\left(\chi^{2}=10.13, \mathrm{df}=12, \mathrm{p}=\right.$ $0.605)$, indicating that being newly tagged does not affect the probability of being recaptured. However, the model failed to pass TEST3.Sm for males $\left(\chi^{2}=25.97, \mathrm{df}=11, \mathrm{p}=0.007\right)$, indicating that newly tagged males have a slightly lower recapture probability the year after first capture compared to previously tagged males. The model passed TEST3.Sm for females $\left(\chi^{2}=10.93, \mathrm{df}=11\right.$, $\mathrm{p}=0.449$ ), indicating that for females transience was not a problem. The model failed to pass TEST2 ('the catchability test') for both sexes combined $\left(\chi^{2}=\right.$ 149.72, df $=62, \mathrm{p}<0.001)$, indicating heterogeneity of recapture probabilities (UCARE TEST2.Ct, trap-dependence statistic for males $=-5.94, \mathrm{p}<0.001$, for females $=$ $-4.07, \mathrm{p}=0.001)$. The negative value of the trap-dependence statistic indicates that the lobsters are 'trap happy'; i.e. previously captured lobsters have a higher recapture probability. When examining the sex-specific difference in detail in the output from TEST2.C (= TEST2.Ct $)$ in RELEASE, 'trap happiness' was significant for males $\left(\chi^{2}=98.93, \mathrm{df}=26, \mathrm{p}<0.001\right)$ and nearly significant for females $\left(\chi^{2}=50.79\right.$, df $=$ $36, \mathrm{p}=0.052$ )

We dealt with the lack of fit demonstrated above by adjustment of c-hat (Anderson et al. 1998). This standard procedure in MARK was done by dividing the overall model $\chi^{2}(=202.0054)$ by the overall degrees of freedom $(=108)$, thus obtaining the chat adjustment factor (1.8704) and the QAICc, on which selection of the best model was based. By far, the most parsimonious model contained a sexdependent linear survival trend and time-dependent recapture probability with an additive effect of sex (Table 1). Females exhibited higher annual apparent survival probability (compared to males) with estimates increasing from 0.663 in 1995 to 0.772 in 2007, corresponding to instantaneous mortality estimates ( $Z=M$, see 'Materials and methods') decreasing from 0.411 to 0.259 . For males, estimates of survival probability increased from 0.592 in 1995 to 0.714 in 2007, corresponding to instantaneous mortality estimates decreasing from 0.524 to 0.337 (Fig. 4a). With the best model, annual recapture probabilities differed between sexes but varied in parallel throughout the duration of the study. Males were more catchable, with estimates of annual recapture probability ranging from 0.339 to 0.631 , geometric mean $=0.471$. For females, estimates ranged from 0.245 to 0.519 , geometric mean $=$ 0.363 (Fig. 4b).

Table 1. Model selection for estimating male and female lobster survival $(\Phi)$ and catchability (P) from capture-mark-recapture data, showing the quasi-likelihood corrected form of the Akaike Information Criterion (QAICC) score, number of parameters, deviance and the final support (QAICc weight) in favor of each candidate model. The most parsimonious model (\#10) is indicated in bold

\begin{tabular}{|c|c|c|c|c|c|}
\hline $\begin{array}{l}\text { Model } \\
\text { no. }\end{array}$ & Model structure & $\begin{array}{r}\text { QAICc } \\
p\end{array}$ & $\begin{array}{l}\text { No. o } \\
\text { ramet }\end{array}$ & Peviance & Support \\
\hline \multicolumn{6}{|c|}{ The Cormack-Jolly-Seber model } \\
\hline 1 & $\Phi_{\text {time } \times \text { sex }}, \mathrm{P}_{\text {time } \times \text { sex }}$ & 6646.3 & 52 & 882.5 & 0.000 \\
\hline \multicolumn{6}{|c|}{ Modeling recapture probabilities } \\
\hline 2 & $\Phi_{\text {time } \times \text { sex }}, \mathrm{P}_{\text {time }+ \text { sex }}$ & 6627.1 & 39 & 889.8 & 0.000 \\
\hline 3 & $\Phi_{\text {time } \times \text { sex }}, \mathrm{P}_{\text {time }}$ & 6645.4 & 38 & 910.1 & 0.000 \\
\hline 4 & $\Phi_{\text {time x sex }}, \mathrm{P}_{\text {sex }}$ & 6645.1 & 28 & 930.0 & 0.000 \\
\hline 5 & $\Phi_{\text {time } \times \text { sex }}, \mathrm{P}$ & 6662.0 & 27 & 948.9 & 0.000 \\
\hline \multicolumn{6}{|c|}{ Modeling survival probabilities } \\
\hline 6 & $\Phi_{\text {time + sex }}, \mathrm{P}_{\text {time }+ \text { sex }}$ & 6614.0 & 28 & 898.9 & 0.001 \\
\hline 7 & $\Phi_{\text {time }}, \mathrm{P}_{\text {time }}+$ sex & 6624.8 & 27 & 911.7 & 0.000 \\
\hline 8 & $\Phi_{\text {sex }}, \mathrm{P}_{\text {time }}+$ sex & 6606.1 & 16 & 915.2 & 0.062 \\
\hline 9 & $\Phi, \mathrm{P}_{\text {time }}+$ sex & 6618.7 & 15 & 929.8 & 0.000 \\
\hline 10 & $\Phi_{\text {sex }+ \text { trend }} \mathbf{P}_{\text {time + sex }}$ & 6600.6 & 17 & 907.7 & 0.934 \\
\hline 11 & $\Phi_{\text {trend }}, \mathrm{P}_{\text {time }}+\mathrm{sex}$ & 6612.3 & 16 & 921.4 & 0.003 \\
\hline
\end{tabular}



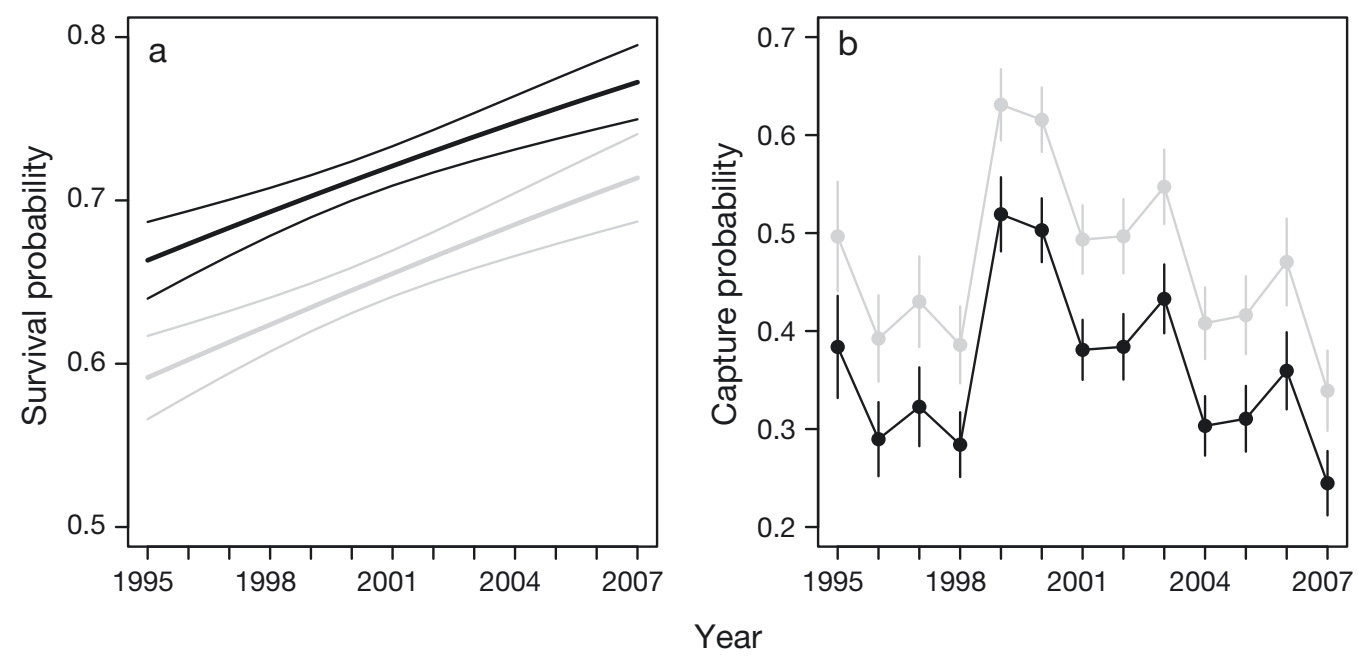

Fig. 4. Homarus gammarus. (a) Annual survival and (b) capture probability for male (grey) and female (black) lobsters from the Kåvra reserve, showing both the mean prediction and the associated SE from the most parsimonious capture-markrecapture model (Table 1, model \#10)

\section{DISCUSSION}

This study demonstrates a lasting increase in survival of protected European lobster 5 to $18 \mathrm{yr}$ after the MPA was established in 1989. Positive trends were also evident in mean body size and in CPUE, and we consider the latter to indicate an increase in abundance of lobsters (see Hoskin et al. 2011, Moland et al. 2013). These findings suggest that processes such as density-dependent body growth (Lorenzen \& Enberg 2002), density-dependent survival (Fromentin et al. 2001) and spatial limitation to settlement (Wahle \& Steneck 1991, Steneck 2006) have yet to come into play after $18 \mathrm{yr}$ of protection. Our study was limited by the fact that no control areas outside the MPA were monitored by capturemark-recapture; hence, there remains the possibility that the observed demographic changes were not a result of protection. Thus, the present study should not be considered as an MPA assessment per se. Rather, the present work represents a study of demographic processes based on interpretation of a capture-mark-recapture data set on European lobster sampled in an MPA. However, data from voluntary catch diaries provided from lobster fishers operating in the vicinity of the Kåvra MPA indicate a decline in CPUE outside the MPA (see Fig. 3b) during the same time period as our study (Sundelöf et al. 2013). Further, on a broader geographical scale, there is no evidence for a rebound of lobster populations on the Norwegian side of Skagerrak, where data collected by selected fishers indicate that CPUE in harvested areas remained at historically low levels (of less than 0.1 lobster per trap per day) during the same time period (Pettersen et al. 2009). We therefore argue that our study provides new and important information about underlying demographic parameters in a harvested species, revealed by removal of harvest pressure. This is corroborated by a recent beforeafter control-impact study that evaluated effects of small-scale Skagerrak MPAs $(\mathrm{n}=3)$ on European lobster (Moland et al. 2013). In that study, the authors reported a mean increase in lobster CPUE of $245 \%$ $(\approx 3.5$-fold) in MPAs compared to a mean increase of $87 \%$ in control areas over $4 \mathrm{yr}$ after MPA designation (2007 to 2010). In this study, the long-term increase in survival suggests that the protected part of the population is gradually becoming more robust towards natural environmental stress during the absence of harvesting. This could be linked to the fact that the mean body size of lobsters, and probably also age, has increased throughout the study period. Anderson et al. (2008) showed that harvesting can lead to increased instability in population dynamics through 'juvenescence' and subsequent changes in demographic parameters. Our findings support this conclusion by showing that protection was associated with a long-term decrease in natural mortality. However, it remains to be shown whether this mechanism is indicative of increased stability in population dynamics.

Herein we present strong evidence, for the first time, for a lasting decadal-scale reduction of natural mortality rate in a protected marine population. 
Recently, Díaz et al. (2011) demonstrated a lasting decadal-scale increase in mean female reproductive output in the spiny lobster Palinurus elephas in a Mediterranean MPA. After implementation of marine reserves, direct effects of protection such as increased mean size and abundance commonly develop rapidly (1 to $5 \mathrm{yr}$ ) for intensively harvested populations (see Babcock et al. 2010). However, in some cases, population recovery was more effective in old (>15 yr) reserves (e.g. Claudet et al. 2008). Decadal-scale time lags have been observed in both direct and indirect effects (e.g. trophic cascades) of protection (Micheli et al. 2004, Babcock et al. 2010).

This study also demonstrates that female lobsters exhibited higher survival probabilities and lower recapture probabilities than males. A similar pattern has been seen for the spiny lobster Palinurus elephas in a Mediterranean MPA (Goñi et al. 2010). Femalebiased survival seems to be the most prevalent pattern in marine species across taxa (e.g. Antarctic krill Euphausia superba [Kawaguchi et al. 2007], arrowtooth flounder Atheresthes stomias [Wilderbuer \& Turnock 2009], humpback whale Megaptera novaeanglicae [Ramp et al. 2010]). However, in marine systems, such patterns are commonly interpreted from catch-at-age data and rarely estimated directly. In life history theory, the expectation for both survival and reproduction is represented by the concept of residual reproductive value (i.e. an organism's capacity or likelihood for future reproductive success) (Stearns 1992). Future survival and reproduction are generally expected to trade off against each other (Reznick et al. 2000), often resulting in life expectancies that differ between sexes. Selection may have favoured faster growth, shorter life spans and more risk-prone lifestyles in male European lobster, whereas longevity and risk-aversive behaviours (e.g. sheltering more while brooding) have been favoured in females. Decreased male survival could be linked to boldness, i.e. a higher propensity of males to engage in potentially risky behaviours such as dispersal, fighting and roaming. When passive gear such as lobster traps is used, increased lobster movement is considered to result in increased catchability. However, Skog (2009) found more high-level aggression in female-female fights than in malemale fights in European lobsters of similar size, contrary to the belief that male lobsters are more aggressive than females. Conversely, the difference in mean size between males and females in Kåvra could also produce sex-specific differences in aggressive behaviours if the notion that larger lobsters are more aggressive than smaller conspecifics holds.
Mean body size and CPUE within the MPA increased throughout the study period. However, the data for both measures indicated inflection points in 2000, with mean body size increasing less steeply thereafter and CPUE stabilizing at a lower level than measured in 1999 before increasing again from 2004 (see Fig. 3a,b). The year 2000 was the first in which traps were used as the sole sampling gear. Before that, shellfish fyke nets had been used until traps were introduced alongside the nets in 1999. Possibly, a difference in gear selectivity was responsible for the inflection points in mean body size and CPUE data.

\section{Catchability and trap dependence}

The highly variable pattern in annual estimates of catchability underscores the importance of long-term sampling in studies using trapping data to draw inferences regarding lobster population dynamics. Estimates of catchability peaked in 1999, the last year in which shellfish fyke nets were used and also the year in which traps were introduced as sampling gear (see Fig. 4b). It seems likely that the combination of gears and their differences in gear selectivity acted in concert to produce the particularly high estimate obtained for this year. Conversely, catchability was only marginally lower in 2000, the year in which traps took over as the sole sampling gear.

Although more pronounced in males, trap dependence in the form of 'trap happiness' was found for both sexes. It is important to note that 'trap happiness' in the present study is long term, acting among years rather than within sampling season, and indicates that previously captured lobsters have a higher recapture probability than newly tagged lobsters. Interpretation of trap-dependent effects can be difficult (Pradel 1993, Crespin et al. 2008). Bjorndal et al. (2003b) found 'trap happiness' in a study involving capture-mark-recapture of green turtles Chelonia mydas in the Bahamas. They concluded that the only explanation why their data structure mimicked trap dependence was a very high recapture probability in their study site resulting from its small area and shallow waters. In the present study, 'trap happiness' could be explained in at least 3 ways, 1 extrinsic and 2 intrinsic: (1) sampling design (extrinsic), where some areas within the MPA were more extensively sampled than others; (2) temporary emigration (intrinsic), where lobsters leave the area for a period before returning; or (3) long-term variability in catchability of lobsters remaining in the area (intrinsic), linked to the moult cycle. We consider the first expla- 
nation to be highly likely. Within the Kåvra MPA, habitat quality and lobster density are spatially variable. Although gear was shifted around in the MPA during the sampling season, this fact may still have developed a tendency to deploy gear in areas where lobsters were more readily caught. In light of the high degree of site fidelity documented in this species (see below), it is likely that the consequence of this tendency was a higher risk of capture for lobsters whose home range was in good lobster habitat and, thus, more frequented by sampling gears (see Crespin et al. 2008 and references therein). In a shorter-term study, Geraldi et al. (2009) found that American lobsters were more likely to be caught in the same location when on rocky habitats than on open sediment habitat. The second explanation seems unlikely, since Homarus gammarus tend to display long-term site fidelity (Dannevig 1936, Smith et al. 2001, Moland et al. 2011). The third explanation has more support, as different species of spiny and clawed lobsters are shown to have highly variable catchability over time. This variability is often attributed to differences in temperature, where catchability usually declines with temperature (e.g. Dannevig 1936, Morgan 1974, Ziegler et al. 2003). As lobsters grow large, they moult less frequently (Chang et al. 2012). Larger individuals that are between moults for an extended period may thus exhibit elevated catchability in subsequent years. However, a marked strength of the present study with regard to catchability is the fact that annual sampling was conducted over an extended field season (May to October). This should have accounted for some of the individual variability in probability of capture, as lobsters that were non-catchable in the beginning of the sampling season (e.g. because of moulting) might well have become catchable by the end of it and vice versa.

\section{Emigration from the MPA}

We estimated apparent survival, $\Phi$, which represents the combined probability of surviving and remaining available for capture within the study area. The sparseness of tag returns from lobster fishers operating in the surrounding waters (see Fig. 2) indicates that permanent emigration from the Kåvra MPA is probably limited and, hence, that apparent survival may be an adequate approximation of true survival. There is an active fishery for lobster in the archipelago near Kåvra from late September to the end of March, with peak intensity from late September to early December (Øresland \& Ulmestrand
2013). Some lobster fishers operating in this and other areas along the Swedish west coast have kept and reported voluntary catch diaries throughout the study period (see Sundelöf et al. 2013). Based on a history of communication and cooperation between The Institute of Marine Research, Lysekil and local fishers, it is likely that the vast majority of recoveries have indeed been reported by fishers (Øresland \& Ulmestrand 2013). We note that the 101 recoveries reported from outside MPA borders, which in fact constitute $\approx 7 \%$ of all recaptures, as quantified herein, are indicative of limited spillover from the Kåvra MPA. However, we cannot rule out the possibility of additional undetected spillover throughout the study period representing a source of bias in our survival estimates. A sampling regime including areas near the MPA would have been useful in elucidating movement across boundaries.

\section{Survival within the MPA}

When inferring that permanent emigration of lobsters is low from the Kåvra MPA, our survival estimates based on the capture-mark-recapture modelling approach, even for the last year $(2007, \approx 71$ and $\approx 77 \%$ for males and females, respectively), are somewhat lower than what has been proposed for Homarus gammarus in previous studies (see below). Tag loss is a factor that will deflate survival estimates. In a tag retention study, Agnalt et al. (2007) reported streamer tag loss in $3 \%$ of $H$. gammarus over a 6 mo period. A field study in which rock lobster Jasus edwardsii were tagged ventrally with Tbar anchor tags (same method as used in the present study) reported 6 and $12 \%$ annual tag loss in females and males, respectively (McGarvey 2004). Consequently, tag loss is a likely source of bias in the present study even though individuals were recaptured with the tag intact after up to $10 \mathrm{yr}$ at large. For comparison, Bevacqua et al. (2010) reported an annual survival probability of $76 \%$ (combined sexes) for a protected population of spiny lobster Palinurus elephas based on size distribution data. In a recent capture-mark-recapture study, the somewhat higher annual survival probabilities of 80 and $84 \%$ for males and females, respectively, were estimated for another protected population of the same species in a reserve of considerably larger size (Goñi et al. 2010). We note that the temporal change detected by our model could be somewhat related to the tagging. Rates of tag loss and tag-induced mortality could be larger over the first, or first few, moults after tagging. 
As the proportion of newly tagged lobsters declined through time, the impact of tagging might have become less apparent and caused estimates of mortality to decrease.

For lobster species in general, estimates of natural mortality have proven difficult to obtain in the past and remain elusive. In cases where attempts have been made through modelling of capture-markrecapture data, the estimated $M$ has been low $\left(<0.1 \mathrm{yr}^{-1}\right)$ and usually associated with relatively large SEs (Latour et al. 2003). For American lobster Homarus americanus, the well-studied congener of H. gammarus, few attempts have been made at estimating mortality rates, and to the best knowledge of the present authors, none have been made at estimating $M$ directly (but see Dunnington et al. 2005). Previously, the most reliable estimates of $M$ for $H$. gammarus were those generated from longevity data $\left(M=0.08\right.$ and $0.15 \mathrm{yr}^{-1}$ for males and females, respectively; Sheehy et al. 1999). Considering the extreme longevities proposed for this species (Sheehy et al. 1999), the survival estimates presented in this study might seem too low. However, extreme longevity in certain individuals from a limited area is not necessarily representative for the species as a whole. Conversely, it is likely that the largest size component of lobsters present in Kåvra is severely underrepresented in the data set due to lower catchability in conventional traps.

\section{Implications for management}

Currently, the lobster management regime in both eastern and western parts of Skagerrak is biased towards conservation of females through the ban on capture and trade of ovigerous lobsters. This management rule, which is imposed with the aim of facilitating recruitment, is likely to inflict a skewed sex ratio through the targeting of males. Moreover, it is accepted that regulations on minimum size and protection of egg-bearing females (common in managed lobster fisheries) select for early maturation and slow growth, because fishing mortality increases with size (Caputi et al. 2010). Our finding that females have higher survival than males in the absence of harvesting may be indicative of a skewed sex ratio under natural conditions, in which females to some degree might outnumber males. This provides further support to the argument that managers should not rely entirely on a ban on capture of ovigerous females when designing conservation measures for depleted lobster stocks.
Increased survival throughout the study period is probably closely linked to the fact that mean body size and age has increased in the population. Recovery of age and size structure is likely to benefit the reproductive potential within the MPA (see Díaz et al. 2011). Based on this knowledge, we recommend an introduction of a maximum size limit (slot limit) in harvested populations of European lobster. Besides countering effects of fisheries-induced selection, conservation of large and presumably old individuals will increase the proportion of individuals experiencing lowered levels of natural mortality and will thus likely act to improve stock resilience.

The parallel increase in survival, body size and abundance (CPUE) throughout the study period strongly suggests that shelter availability and competition for resources have not yet become limiting factors in the Kåvra reserve lobster population, i.e. the effects of density-dependent processes envisaged to result from long-term protection (Gårdmark et al. 2006) have not materialised. If the opposite had been the case, we would have observed a greater amount of emigration driven by 'demographic diffusion', proposed and experimentally evaluated for Homarus americanus, where larger lobsters leave or avoid areas of high lobster population density and intense competition for areas of low population density and relaxed competition (Steneck 2006). If present in $H$. gammarus, this effect should have had time to develop, as extractive fishing has been absent in the reserve since 1989. Conversely, our results indicate that we have limited understanding of pristine population density levels in European lobster and that historical anecdotes of high lobster densities near shore are indeed realistic (Dannevig 1936). This could well be the case for some species and stocks, intensively exploited for centuries, for which we lack scientific data on pristine population density levels. Our study underscores the need for, and value of, well designed and replicated MPA experiments involving the capture-mark-recapture methodology to more fully assess the demographic effects of protection on marine populations.

Acknowledgements. We are indebted to H. Hallbäck for his central role in conducting the impressive trapping and tagging work financed by the Swedish Board of Fisheries. We thank J. Claudet, A. J. Frisch, R. Goñi, L. Gonzales, S. H. Jury, R. Lipcius and 5 anonymous reviewers for providing valuable comments on previous versions of this manuscript. This work was supported by the Research Council of Norway (RCN, through grant \# 173432/S40 and 201917/F20). E.M. thanks R. S. Steneck, G. P. Jones and colleagues for 
helpful discussions during an overseas fellowship (supported by RCN) to James Cook University, Australia, where the main part of the writing of this article took place.

\section{LITERATURE CITED}

Agnalt AL (2008) Fecundity of the European lobster (Homarus gammarus) off southwestern Norway after stock enhancement: do cultured females produce as many eggs as wild females? ICES J Mar Sci 65:164-170

Agnalt AL, Kristiansen TS, Jørstad KE (2007) Growth, reproductive cycle, and movement of berried European lobsters (Homarus gammarus) in a local stock off southwestern Norway. ICES J Mar Sci 64:288-297

Anderson DR, Burnham KP, White GC (1998) Comparison of the Akaike Information Criterion and consistent Akaike Information Criterion for model selection and statistical inference from capture-recapture studies. J Appl Stat 25: 263-282

Anderson CNK, Hsieh CH, Sandin SA, Hewitt R and others (2008) Why fishing magnifies fluctuations in fish abundance. Nature 452:835-839

Babcock RC, Shears NT, Alcala AC, Barret NS and others (2010) Decadal trends in marine reserves reveal differential rates of change in direct and indirect effects. Proc Natl Acad Sci USA 107:18256-18261

> Baskett ML, Levin SA, Gaines SD, Dushoff J (2005) Marine reserve design and the evolution of size at maturation in harvested fish. Ecol Appl 15:882-901

> Beamish RJ, McFarlane GA, Benson A (2006) Longevity overfishing. Prog Oceanogr 68:289-302

> Berkeley SA, Hixon MA, Larson RJ, Love MS (2004) Fisheries sustainability via protection of age structure and spatial distribution of fish populations. Fisheries 29: 23-32

> Bevacqua D, Melià P, Follesa MC, De Leo GA, Gatto M, Cau A (2010) Body growth and mortality of the spiny lobster Palinurus elephas within and outside a small marine protected area. Fish Res 106:543-549

Bjorndal KA, Bolten AB, Martins HR (2003a) Estimates of survival probabilities for oceanic-stage loggerhead sea turtles (Caretta caretta) in the North Atlantic. Fish Bull 101:732-736

Bjorndal KA, Bolten AB, Chaloupka MY (2003b) Survival probability estimates for immature green turtles Chelonia mydas in the Bahamas. Mar Ecol Prog Ser 252: 273-281

Burnham KP, Anderson DR, White GC, Brownie C, Pollock KH (1987) Design and analysis methods for fish survival experiments based on release-recapture. Am Fish Soc Monogr 5:1-437

> Caputi N, Melville-Smith R, de Lestang S, Pearce A, Feng M (2010) The effect of climate change on the western rock lobster (Panulirus cygnus) fishery of western Australia. Can J Fish Aquat Sci 67:85-96

Chang Y, Sun C, Chen Y, Yeh S (2012) Modelling the growth of crustacean species. Rev Fish Biol Fish 22:157-187

Choquet R, Lebreton JD, Gimenez O, Reboulet AM, Pradel R (2009) U-CARE: utilities for performing goodness of fit tests and manipulating CApture-REcapture data. Ecography 32:1071-1074

Claudet J, Osenberg CW, Benedetti-Cecchi L, Domenici P and others (2008) Marine reserves: size and age do matter. Ecol Lett 11:481-489
Crespin L, Choquet R, Lima M, Merritt J, Pradel R (2008) Is heterogeneity of catchability in capture-recapture studies a mere sampling artifact or a biologically relevant feature of the population? Popul Ecol 50:247-256

Dannevig A (1936) Lobster and lobster culture. Report on Norwegian fishery and marine investigations, Vol. 4, No. 12. Director of Fisheries, Bergen (in Norwegian)

- Díaz D, Mallol S, Parma AM, Goñi R (2011) Decadal trend in lobster reproductive output from a temperate marine protected area. Mar Ecol Prog Ser 433:149-157

Dunnington MJ, Wahle RA, Bell MC, Geraldi NR (2005) Evaluating local population dynamics of the American lobster, Homarus americanus, with trap-based markrecapture methods and seabed mapping. NZ J Mar Fresh 39:1253-1276

Edgar GJ, Barret NS (1999) Effects of the declaration of marine reserves on Tasmanian reef fishes, invertebrates and plants. J Exp Mar Biol Ecol 242:107-144

Follesa MC, Cuccu D, Cannas R, Sabatini A, Deiana AM, Cau A (2009) Movement patterns of the spiny lobster Palinurus elephas (Fabricius, 1787) from a central western Mediterranean protected area. Sci Mar 73:499-506

- Francis RC, Hixon MA, Clarke ME, Murawski SA, Ralston S (2007) Fisheries management: ten commandments for ecosystem-based fisheries scientists. Fisheries 32: 217-233

> Fromentin JM, Myers RA, Bjornstad ON, Stenseth NC, Gjøsæter J, Christie H (2001) Effects of density-dependent and stochastic processes on the regulation of cod populations. Ecology 82:567-579

Game ET, Grantham HS, Hobday AJ, Pressey RL and others (2009) Pelagic protected areas: the missing dimension in ocean conservation. Trends Ecol Evol 24:360-369

Gårdmark A, Jonzen N, Mangel M (2006) Density-dependent body growth reduces the potential of marine reserves to enhance yields. J Appl Ecol 43:61-69

Geraldi NR, Wahle RA, Dunnington MJ (2009) Habitat effects on American lobster catch and movement: insights from geo-referenced trap arrays, seabed mapping, and tagging. Can J Fish Aquat Sci 66:460-470

Goñi R, Quetglas A, Reñones O (2006) Spillover of spiny lobsters Palinurus elephas from a marine reserve to an adjoining fishery. Mar Ecol Prog Ser 308:207-219

Goñi R, Hilborn R, Díaz D, Mallol S, Adlerstein S (2010) Net contribution of spillover from a marine reserve to fishery catches. Mar Ecol Prog Ser 400:233-243

Halpern BS, Warner RR (2003) Matching marine reserve design to reserve objectives. Proc Biol Sci 270:1871-1878

Hoskin MG, Coleman RA, von Carlshausen E, Davis CM (2011) Variable population responses to the establishment of a temperate no-take zone. Can J Fish Aquat Sci 68:185-200

> Jones PJS (2007) Point-of-view: arguments for conventional fisheries management and against no-take marine protected areas: Only half of the story? Rev Fish Biol Fish 17: 31-43

Kawaguchi S, Finley LA, Jarman S, Candy SG and others (2007) Male krill grow fast and die young. Mar Ecol Prog Ser 345:199-210

> Latour RJ, Hoenig JM, Hepworth DA, Frusher SD (2003) A novel tag-recovery model with two size classes for estimating fishing and natural mortality, with implications for the southern rock lobster (Jasus edwardsii) in Tasmania, Australia. ICES J Mar Sci 60:1075-1085

> Lebreton JD, Burnham KP, Clobert J, Anderson DR (1992) 
Modeling survival and testing biological hypotheses using marked animals: a unified approach with case studies. Ecol Monogr 62:67-118

Lizaso JLS, Goñi R, Reñones O, Charton G and others (2000) Density dependence in marine protected populations: a review. Environ Conserv 27:144-158

Lorenzen K, Enberg K (2002) Density-dependent growth as a key mechanism in the regulation of fish populations: evidence from among-population comparisons. Proc R Soc Lond B Biol Sci 269:49-54

Lubchenco J, Palumbi SR, Gaines SD, Andelman S (2003) Plugging a hole in the ocean: the emerging science of marine reserves. Ecol Appl 13:S3-S7

McCullagh P, Nelder JA (1999) Generalized linear models. Chapman \& Hall/CRC, London

McGarvey R (2004) Estimating the emigration rate of fish stocks from marine sanctuaries using tag-recovery data. Fish Bull 102:464-472

Micheli F, Halpern B, Botsford LW, Warner RR (2004) Trajectories and correlates of community change in no-take marine reserves. Ecol Appl 14:1709-1723

Moland E, Olsen EM, Andvord K, Knutsen JA, Stenseth NC (2011) Home range of European lobster (Homarus gammarus) in a marine reserve: implications for future reserve design. Can J Fish Aquat Sci 68:1197-1210

Moland E, Olsen EM, Knutsen H, Garrigou P and others (2013) Lobster and cod benefit from small-scale northern marine protected areas: inference from an empirical before-after control-impact study. Proc R Soc Lond B Biol Sci 280:20122679

Morgan GR (1974) Aspects of population-dynamics of western rock lobster, Panulirus cygnus George. II. Seasonal changes in the catchability coefficient. Aust J Mar Freshwater Res 25:249-259

Øresland V, Ulmestrand M (2013) European lobster subpopulations from limited adult movements and larval retention. ICES J Mar Sci 70:532-539

Pettersen AR, Moland E, Olsen EM, Knutsen JA (2009) Lobster reserves in coastal Skagerrak-an integrated analysis of the implementation process. In: Dahl E, Moksness E, Støttrup J (eds) Integrated coastal zone management. Wiley-Blackwell Publishing, London, p 178-188

Pradel R (1993) Flexibility in survival analysis from recapture data: handling trap-dependence. In: Lebreton JD, North PM (eds) Marked individuals in the study of bird populations. Birkhäuser Verlag, Basel, p 29-37

Ramp C, Bérubé M, Palsbøll P, Hagen W, Sears R (2010) Sexspecific survival in the humpback whale Megaptera novaeangliae in the Gulf of St. Lawrence, Canada. Mar Ecol Prog Ser 400:267-276

Reznick D, Nunney L, Tessier A (2000) Big houses, big cars,

Editorial responsibility: Romuald Lipcius,

Gloucester Point, Virginia, USA superfleas and the costs of reproduction. Trends Ecol Evol 15:421-425

Rowe S (2002) Population parameters of American lobster inside and outside no-take reserves in Bonavista Bay, Newfoundland. Fish Res 56:167-175

Russ GR, Cheal AJ, Dolman AM, Emslie MJ and others (2008) Rapid increase in fish numbers follows creation of world's largest marine reserve network. Curr Biol 18: R514-R515

> Sheehy MRJ, Bannister RCA, Wickins JF, Shelton PMJ (1999) New perspectives on the growth and longevity of the European lobster (Homarus gammarus). Can J Fish Aquat Sci 56:1904-1915

Skog M (2009) Intersexual differences in European lobster (Homarus gammarus): recognition mechanisms and agonistic behaviours. Behaviour 146:1071-1091

Smith IP, Jensen AC, Collins KJ, Mattey EL (2001) Movement of wild European lobsters Homarus gammarus in natural habitat. Mar Ecol Prog Ser 222:177-186

Stearns SC (1992) The evolution of life histories. Oxford University Press, Oxford

> Steneck RS (2006) Possible demographic consequences of intraspecific shelter competition among American lobsters. J Crustac Biol 26:628-638

> Sundelöf A, Bartolino V, Ulmestrand M, Cardinale M (2013) Multi-annual fluctuations in reconstructed historical time-series of a European lobster (Homarus gammarus) population disappear at increased exploitation levels. PLoS ONE 8:e58160

> Triantafyllidis A, Apostolidis AP, Katsares V, Kelly E and others (2005) Mitochondrial DNA variation in the European lobster (Homarus gammarus) throughout the range. Mar Biol 146:223-235

Wahle RA, Steneck RS (1991) Recruitment habitats and nursery grounds of the American lobster Homarus americanus: A demographic bottleneck? Mar Ecol Prog Ser 69:231-243

> White GC, Burnham KP (1999) Program MARK: survival estimation from populations of marked animals. Bird Study 46:S120-S139

- Wilderbuer TK, Turnock BJ (2009) Sex-specific natural mortality of arrowtooth flounder in Alaska: implications of a skewed sex ratio on exploitation and management. N Am J Fish Manag 29:306-322

> Worm B, Hilborn R, Baum JK, Branch TA and others (2009) Rebuilding global fisheries. Science 325:578-585

Ziegler PE, Frusher SD, Johnson CR (2003) Space-time variation in catchability of southern rock lobster Jasus edwardsii in Tasmania explained by environmental, physiological and density-dependent processes. Fish Res $61: 107-12$

Submitted: November 5, 2012; Accepted: June 25, 2013 Proofs received from author(s): September 16, 2013 